\title{
The effect of rural-to-urban migration on renal function in an Indian population: cross-sectional data from the Hyderabad arm of the Indian Migration Study
}

\author{
Phillippa K Bailey ${ }^{1 *}$, Charles RV Tomson1', Sanjay Kinra², Shah Ebrahim², KV Radhakrishna ${ }^{3}$, Hannah Kuper², \\ Dorothea Nitsch ${ }^{2}$ and Yoav Ben-Shlomo ${ }^{4}$
}

\begin{abstract}
Background: Urban migration is associated with an increased risk of hypertension, obesity and diabetes in Indian migrants. This study assessed the relationship between internal migration and renal function in the Hyderabad arm of the Indian Migration Study.

Methods: We assessed 841 subjects; urban non-migrants $(n=158)$, urban migrants $(n=424)$ and rural non-migrants $(n=259)$. Muscle mass was ascertained from DXA scanning. We derived urban life years for urban migrants and rural non-migrants. Multivariable linear regression was used to examine the association between tertiles of urban life years and 4-variable MDRD eGFR using Stata 11.

Results: Mean eGFR was lower in urban non-migrants and urban migrants compared to rural non-migrants. The prevalence of CKD 3-5 was higher in the rural non-migrant population (5.0\%) than in the urban non-migrant populations (2.5\%) due to a negatively skewed distribution of eGFR in rural non-migrants. As urban life years increased, eGFR declined $(p=0.008)$ though there was no obvious dose response effect. After adjustment for muscle mass, the association was attenuated and the trend was consistent with chance $(p=0.08)$. Further adjustment for vascular risk factors weakened the association to a small degree $(p=0.11)$.
\end{abstract}

Conclusions: The high prevalence of reduced eGFR in rural areas requires further research. Urbanization was associated with reduced eGFR. This association appears mostly to be due to higher muscle mass with a small contribution from adverse vascular disease risk factors.

\section{Background}

In comparison to host populations, migrants are more frequently subject to hypertension, obesity and chronic conditions such as diabetes [1]. Migrants' ill-health and unfavourable risk profiles may worsen with increasing duration of stay [1]. In addition, urban populations have higher levels of cardiometabolic risk factors than rural populations [2-5] and rural to urban migration has been shown to be associated with an accruement of these risk factors [6,7]. Trends of increased obesity and diabetes among international South Asian migrants are well

\footnotetext{
* Correspondence: pippabailey@hotmail.com

'The Richard Bright Renal Unit, Southmead Hospital, Bristol BS10 5NB, UK Full list of author information is available at the end of the article
}

documented $[8,9]$ and more recently have been demonstrated among internal rural-urban migrants in India [6,7]. Studies of renal function among South Asian populations living in the UK have shown higher acceptance rates for renal replacement treatment [10], which is probably secondary to a higher incidence of end-stage renal failure. This may be partly due to a higher prevalence of Type 2 diabetes and an increased risk of renal failure as a complication [11] but it is difficult in the UK to distinguish between the health effects of migration, and socio-cultural and ethnic differences in an epidemiological study. We have studied the effect of rural-to-urban migration on renal function within India. To date there has been no previous work published in this area. 
Until recently, information on the prevalence and incidence of Chronic Kidney Disease (CKD) in India was limited to small studies, comparisons between which were limited by differences in study populations, methods of measuring or estimating renal function and definitions of CKD [12-14]. The Indian Renal Registry published its first report in 2012. The most common identifiable causes of CKD were diabetes, glomerulonephritis and hypertension [15]. 'Unknown aetiology' was the second most common 'diagnosis' after diabetes. It is not possible to determine from existing registry data whether there are differences in CKD prevalence between urban and rural areas.

The aim of this study was to look at differences in estimated Glomerular Filtration Rate (eGFR) between rural non-migrants, urban non-migrants and rural-to-urban migrants (urban migrants) within India, and to understand the reasons behind any differences observed. Differences in muscle mass between urban and rural populations may result in differences in creatinine-based eGFR. In this study we had the benefit of whole body Dual-energy X-ray Absorptiometry (DXA) scans and were therefore able to adjust findings for measured muscle mass.

It was hypothesized that urbanization would have a negative effect on eGFR, and that those living in an urban area, would have worse renal function, represented by a lower eGFR, than rural non-migrants. We expected the effects of urbanization to accrue and that in urban migrants, controlling for age, the greater the time spent in an urban environment, the lower eGFR. We expected the effect of urbanization to be the result of increased vascular disease and cardiometabolic risk factors.

\section{Methods}

\section{Ethics statement}

Ethics committee approval was obtained from the All India Institute of Medical Sciences Ethics Committee, reference number A-60/4/8/2004.

Using the framework of a cardiovascular risk factor screen study conducted in factories in north, central and south India [16] a sib-pair comparison study was designed. Details of the design have been reported elsewhere [17]. The original study was based in four Indian factories (Lucknow, Hindustan Aeronautics Ltd; Nagpur, Indorama Synthetics Ltd; Hyderabad, Bharat Heavy Electricals Ltd; and Bangalore, Hindustan Machine Tools Ltd). Factory workers and their co-resident spouses were recruited if they were urban migrants using employer records as the sampling frame. Each migrant worker and spouse invited one non-migrant full sibling of the same sex, closest to them in age still residing in their rural place of origin. A $25 \%$ random sample of non-migrants was also invited to participate. Information sheets were translated into local languages, signed (thumb print accepted), and consent obtained. Field work began in March 2005 and was completed by December 2007.

The Hyderabad arm of the Indian Migration Study is a more detailed follow-up study of the original subject from the Hyderabad centre. Participants were invited to a screening clinic at the National Institute of Nutrition between January 2009 and December 2010.

\section{Rural-urban status}

Attempts were made to correct discrepancies in migrant status where the data allowed. Participants were excluded if mislabelling errors could not be corrected (eg participants had been labelled as urban non-migrants with no urban years recorded). In total 76 individuals were excluded due to discrepancies between urban life years and original migrant status.

\section{Clinic measures}

Participants were interviewed and data collected on demographic factors including socioeconomic status by using a subset of 12 of 27 questions from the Standard of Living Index (SLI), a household level asset-based scale devised for Indian surveys [18]. These comprised house type, house ownership, toilet facility, source of lighting, source of drinking water, car or tractor, moped or scooter, telephone, refrigerator, television, bicycle, radio, clock or watch, and weighted to give a maximum score of 33. Weights of items for the SLI were developed by the International Institute of Population Sciences in India. On the basis of this score, individuals were classified as having a 'low' (0-7), 'middle' (812) or 'high' (13-33) standard of living. Smoking was assessed as positive if individuals currently/actively smoked or chewed tobacco. Few individuals reported previous but not current smoking.

A diagnosis of Coronary Heart Disease (CHD) and Stroke was made by self-report of a doctor diagnosis.

Weight was measured twice to the nearest $0.1 \mathrm{~kg}$ without shoes using digital Seca scales (www.seca.com). Standing height was measured twice without shoes using a portable stadiometer (Leicester height measure; Chasmors Ltd, Camden, London, UK). The participant stood erect with his or her head in the Frankfort plane, and a gentle upward pressure was applied under the mastoid. Waist circumference was measured twice to the nearest $\mathrm{mm}$ using a material tape measure at the narrowest point of the waist between the ribs and the iliac crest. The average of the two values was used in the analysis. Body Mass Index (BMI) was calculated as weight $(\mathrm{kg}) / \mathrm{height}(\mathrm{m})^{2}$. We used a validated oscillometric device (OMRON M5-I; Omron, Matsusaka Co, Japan) to measure blood pressure in the sitting position with appropriate cuff sizes. We took three measures, 2-3 minutes apart, and averaged the measures for analyses. A diagnosis of Hypertension was made if the average of three systolic blood pressure (BP) 
measurements was $\geq 140 \mathrm{mmHg}$, if the average of three diastolic BP measurements was $\geq 90 \mathrm{mmHg}$ or if there was report of a doctor diagnosis of Hypertension [19].

\section{Laboratory assays and anthropometric measurements}

Participants were asked to attend fasting and the time of their last meal was recorded. Creatinine analysis was performed using the rate-blanked and compensated Jaffe method for creatinine estimation on a COBAS C311 autoanalyzer from ROCHE. The calibraton for this assay is traceable to isotope dilution mass spectrometry (IDMS), that is, the method used is calibrated to the single standardized serum creatinine using reference materials traceable to the primary reference material at the National Institute of Standards, based on IDMS. The Cardiac Biochemistry Lab, AIIMS, is part of the UK National External Quality Assessment Scheme (www.ukneqas.org.uk) to quality assure its assays.

A diagnosis of diabetes was made using the World Health Organization (WHO) fasting plasma glucose criterion of $>7.0 \mathrm{mmol} / \mathrm{l}$ [20] or report of a doctor diagnosis of diabetes. Homeostasis model assessment (HOMA) scores to estimate insulin resistance were calculated from fasting blood glucose and serum insulin levels using a standard formula of plasma glucose $(\mathrm{mmol} / \mathrm{l}) \times$ plasma insulin $(\mathrm{mU} / \mathrm{l}) / 22.5$, on the basis of the original approach [21]. HOMA has been validated by comparison with biochemical markers of insulin resistance in healthy Indian people, yielding moderate correlations [22]. Low values indicate high insulin sensitivity, whereas high values indicate low insulin sensitivity (insulin resistance).

Whole body DXA scans were performed on a Hologic DXA machine (Discovery A model) (91\% of scans) or a Hologic QDR 4500 Elite machine (www.hologic.com) ( $9 \%$ of scans). Participants were asked to remove jewellery and to change in to light clothing. During the scan, the participant was asked to lie supine on the scanning bed with their arms at their sides. Whole body scans were visually checked for artefacts and those with major artefacts were removed from the analyses. For quality assurance, a spine phantom was scanned every day to check for acceptable ranges. DXA exploits the attenuation of two photo energies to determine the mass of mineral, fat and lean in the body. Wang et al found that lean mass in the extremities represents approximately $75 \%$ of the total body skeletal muscle mass [23]. Thus total skeletal muscle mass was determined from the lean body mass of all four extremities multiplied by 1.33 . Body Surface Area (BSA) was calculated from height and weight with the Mosteller equation [24]. Following previous work to examine the performance of various creatinine-based renal function estimating formulae [25], we estimated renal function using the IDMS standardized
Modification of Diet in Renal Disease (MDRD) formula:

$$
\begin{aligned}
e G F R= & 175 \times\left(\text { Serum creatinine }(m g / d l)^{-1.154} \times \text { Age } e^{-0.203}\right. \\
& \times[0.742 \text { if female }]=m l / \mathrm{min} / 1.73 m^{2}
\end{aligned}
$$

CKD was classified according to the KDOQI guidelines [26]. As information on albuminuria or proteinuria was unavailable, stages 1 and 2 were not identified. We defined an eGFR $<60 \mathrm{ml} / \mathrm{min} / 1.73 \mathrm{~m}^{2}$ as 'CKD stages $3-5$ '. In clinical practice, the diagnosis of CKD requires evidence of reduced function for $\geq 3$ months, however it is accepted in epidemiological studies that a single estimate of GFR is used for a diagnosis of CKD [27].

\section{Statistical analyses}

Linear regression and Pearson's correlation coefficient were used to investigate the relationship between eGFR and age within each group (rural non-migrants, urban migrants and urban non-migrants). We undertook sexstratified analyses as well as combined analyses after formally testing for any sex interaction.

After excluding urban non-migrants, we generated tertiles from urban life years (Tertile 1: 0 years $(\mathrm{n}=228)$ Tertile 2: 0.9 to 28.8 years $(\mathrm{n}=228)$, Tertile $3: 28.8$ to 51.8 years $(\mathrm{n}=227)$ ) and proportion of life in an urban area (Tertile 1: 0 , Tertile 2: 0.01 to 0.57 , Tertile 3: 0.58 to 0.98). It was possible to generate true tertiles as a small number of 'rural non-migrants' although primarily rural dwellers had spent some time living in urban areas $(<0.4$ proportion of life and fewer than 22 years). We performed multivariable linear regression (with tertiles as dummy variables) to calculate the regression coefficient between eGFR and urban life years with rural non-migrants as the baseline comparator group. The analysis was performed both unadjusted and adjusted for vascular disease risk factors and body composition: age, HOMA-IR, diabetes, smoking, cholesterol, BMI, hypertension and DXA measured lean muscle mass.

As the study design includes related individuals, who are not truly independent, we performed our regression models using robust standard errors to allow for any family clustering effect. This provides larger p-values and more conservative standard errors. A sensitivity analysis was repeated with 'proportion of life spent resident in an urban area'. All statistical analyses were performed using Stata version 11.

\section{Results}

917 individuals were eligible for analysis. 76 individuals were excluded from analyses due to discrepancies between urban life years and original migrant status. The study sample comprised 841 adult subjects (mean age $48.4 \pm S$. D. 8.3 years) and roughly equal proportions of men and women in the overall sample and in the subgroups (chi2 $\mathrm{p}$ 
value 0.26 ) (Table 1 ). The BMI of rural non-migrants was $3.4 \mathrm{~kg} / \mathrm{m}^{2}$ lower than that of urban non-migrants $(95 \%$ CI 3.2-3.6). Mean muscle mass in rural non-migrants was $1.2 \mathrm{~kg}$ (95\% CI 1.0-1.3) less than in urban non-migrants. Smoking was more prevalent amongst rural non-migrants $(17.8 \%)$ compared with urban migrants (8.5\%) and urban non-migrants (7.6\%). The prevalence of diabetes and hypertension was lowest in the rural non-migrants. Mean eGFR as estimated by MDRD was lower in urban nonmigrants and urban migrants compared to rural nonmigrants. Rural non-migrants had the highest mean eGFR. However, the prevalence of CKD stages 3-5 was higher in the rural non-migrant population (5.0\%) than in the urban migrant population $(4.2 \%)$ and the urban non-migrant population $(2.5 \%)$. The higher prevalence of those with eGFR $<60 \mathrm{ml} / \mathrm{min} / 1.73 \mathrm{~m}^{2}$ in the rural group is explained by the histogram showing a negatively skewed distribution
(Figure 1). The number of people with CKD stages 3-5 was very small in all groups and the proportions were similar for all groups ( $\mathrm{p}$ value $=0.20$ ).

The relationship between eGFR and age was examined with linear regression in each group (rural non-migrants, urban migrants and urban non-migrants). eGFR declined with increasing age in all groups and no heterogeneity was observed between groups (Additional file 1: Table S1 + Additional file 1: Figure S1).

Linear regression analysis revealed that at any given age, the mean eGFR was $5.9 \mathrm{ml} / \mathrm{min} / 1.73 \mathrm{~m}^{2}(\mathrm{p}=0.007,95 \%$ $\mathrm{CI}-10.1$ to -1.6$)$ lower in urban non-migrants compared to rural non-migrants, and $4.0 \mathrm{ml} / \mathrm{min} / 1.73 \mathrm{~m}^{2}(\mathrm{p}=0.011$, 95\% CI -7.0 to -0.9 ) lower in urban migrants compared to rural non-migrants.

The analysis was then restricted to rural non-migrants and urban migrants to investigate the association of urban

Table 1 Baseline characteristics of Hyderabad arm of the Indian migration study stratified by migration status

\begin{tabular}{|c|c|c|c|c|}
\hline & All & Rural non-migrants & Rural to urban migrants & Urban non-migrants \\
\hline No of observations & 841 & 259 & 424 & 158 \\
\hline \multirow[t]{2}{*}{$\%$ female } & 47.1 & 43.6 & 47.4 & 51.9 \\
\hline & & Mean ( \pm S.D.) & & \\
\hline Age (years) & $48.4( \pm 8.3)$ & $47.5( \pm 10.3)$ & $49.4( \pm 6.7)$ & $46.9( \pm 8.5)$ \\
\hline Weight (kg) & $65.4( \pm 11.9)$ & $61.0( \pm 12.6)$ & $66.8( \pm 10.7)$ & $68.9( \pm 11.9)$ \\
\hline Height (cm) & $159.0( \pm 8.7)$ & $159.0( \pm 8.7)$ & $159.2( \pm 8.5)$ & $158.7( \pm 9.2)$ \\
\hline $\mathrm{BMI}\left(\mathrm{kg} / \mathrm{m}^{2}\right)$ & $25.9( \pm 4.4)$ & $24.1( \pm 4.5)$ & $26.4( \pm 3.9)$ & $27.5( \pm 4.7)$ \\
\hline $\mathrm{BSA}\left(\mathrm{m}^{2}\right)$ & $1.69( \pm 0.18)$ & $1.63( \pm 0.19)$ & $1.71( \pm 0.16)$ & $1.74( \pm 0.17)$ \\
\hline Muscle Mass (kg) & $24.1( \pm 5.4)$ & $23.4( \pm 5.4)$ & $24.4( \pm 5.4)$ & $24.6( \pm 5.2)$ \\
\hline Muscle mass (kg per $1.73 \mathrm{~m}^{2}$ ) & $24.4( \pm 3.6)$ & $24.5( \pm 3.7)$ & $24.4( \pm 3.7)$ & $24.3( \pm 3.5)$ \\
\hline $\mathrm{SBP}(\mathrm{mmHg})$ & $122( \pm 16)$ & $121( \pm 17)$ & $122( \pm 16)$ & $121( \pm 16)$ \\
\hline $\mathrm{DBP}(\mathrm{mmHg})$ & $81( \pm 10)$ & $79( \pm 10)$ & $82( \pm 10)$ & $81( \pm 9)$ \\
\hline Creatinine $(\mu \mathrm{mol} / \mathrm{l})$ & $73.1( \pm 17.7)$ & $72.1( \pm 17.8)$ & $73.7( \pm 18.4)$ & $73.3( \pm 15.7)$ \\
\hline Total cholesterol & $4.9( \pm 1.0)$ & $4.8( \pm 1.1)$ & $4.9( \pm 1.0)$ & $4.8( \pm 1.0)$ \\
\hline HOMA-IR score & $2.74( \pm 5.30)$ & $1.68( \pm 1.94)$ & $3.22( \pm 6.21)$ & $3.21( \pm 6.12)$ \\
\hline \multirow[t]{3}{*}{ MDRD eGFR $\left(\mathrm{ml} / \mathrm{min} / 1.73 \mathrm{~m}^{2}\right)$} & $91.3( \pm 20.5)$ & $94.7( \pm 21.7)$ & $89.8( \pm 19.6)$ & $89.7( \pm 20.1)$ \\
\hline & [95\% Cl 89.9-92.7] & [95\% Cl 91.9-97.4] & [95\% Cl 87.8-91.7] & [95\% Cl 86.5-93.0] \\
\hline & & Number (\%) & & \\
\hline SES-LOW & $15(1.8 \%)$ & $14(5.4 \%)$ & $1(0.2 \%)$ & $0(\%)$ \\
\hline SES-Middle & $43(5.1 \%)$ & $39(15.1 \%)$ & $2(0.5 \%)$ & $2(1.3 \%)$ \\
\hline SES-High & $783(93.1 \%)$ & $206(79.5 \%)$ & $421(99.3 \%)$ & $156(98.7 \%)$ \\
\hline PMH diabetes & $148(17.6 \%)$ & $26(10 \%)$ & 89 (21.0\%) & $33(20.9 \%)$ \\
\hline Diabetes & $207(24.6 \%)$ & $44(17.0 \%)$ & $119(28.1 \%)$ & $44(27.8 \%)$ \\
\hline Hypertension & $300(35.7 \%)$ & $73(28.2 \%)$ & $161(38.0 \%)$ & $66(41.8 \%)$ \\
\hline Smoking status-current & $94(11.1 \%)$ & $46(17.8 \%)$ & $36(8.5 \%)$ & $12(7.6 \%)$ \\
\hline Vascular disease (CHD and Stroke) & $37(4.4 \%)$ & $7(2.7 \%)$ & $24(5.7 \%)$ & $6(3.8 \%)$ \\
\hline MDRD-CKD 3-5 & $35(4.1 \%)$ & $13(5.0 \%)$ & $18(4.2 \%)$ & $4(2.5 \%)$ \\
\hline
\end{tabular}

BMI-Body Mass Index; BSA-Body Surface Area; SBP-systolic blood pressure; DBP-diastolic blood pressure; HOMA-IR-Homeostatic Model Assessment-Insulin Resistance; MDRD eGFR-Modification of Diet in Renal Disease estimated Glomerular Filtration Rate; SES-Socio-Economic Status; PMH-Past Medical History; CHD-Coronary Heart Disease; CKD-Chronic Kidney Disease. 
a)

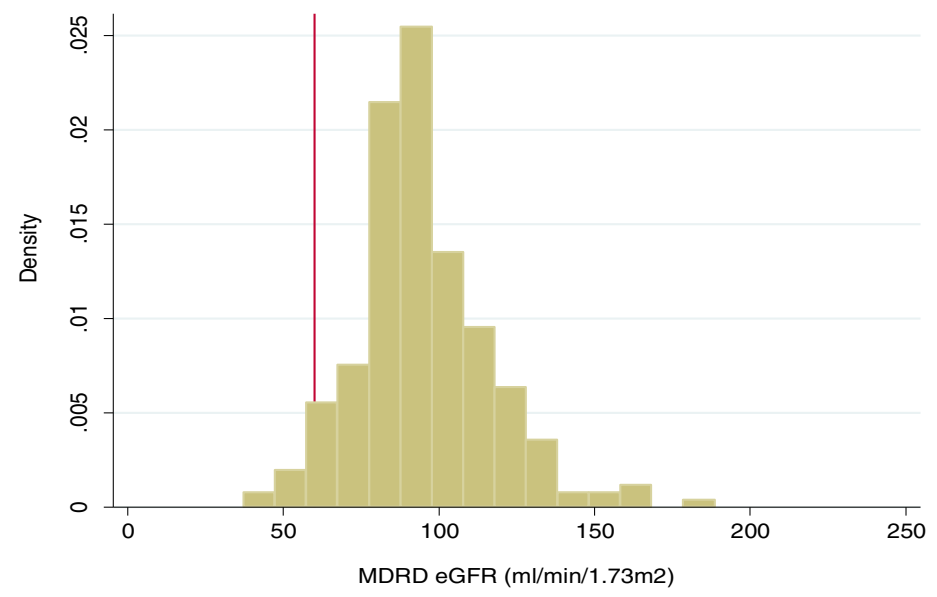

b)

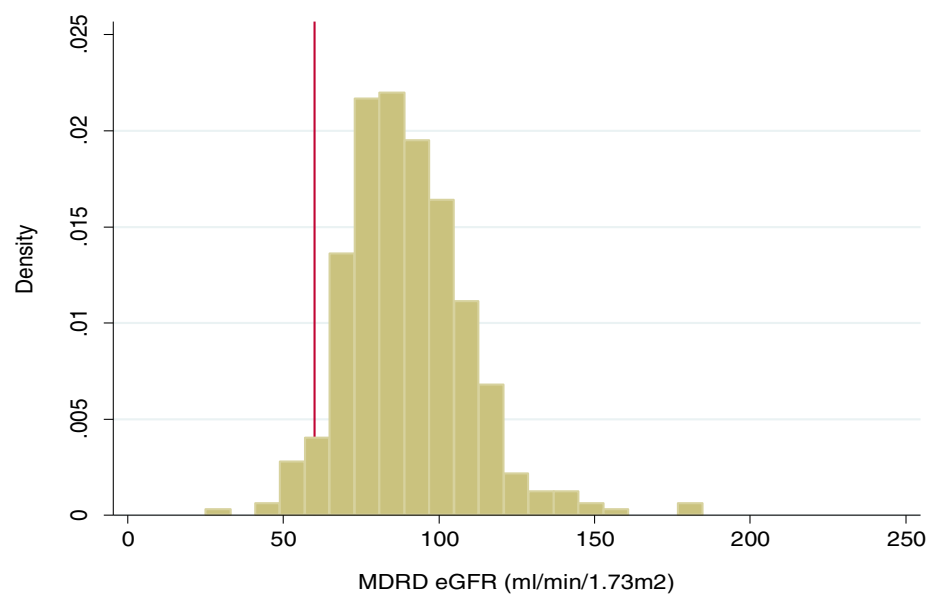

c)

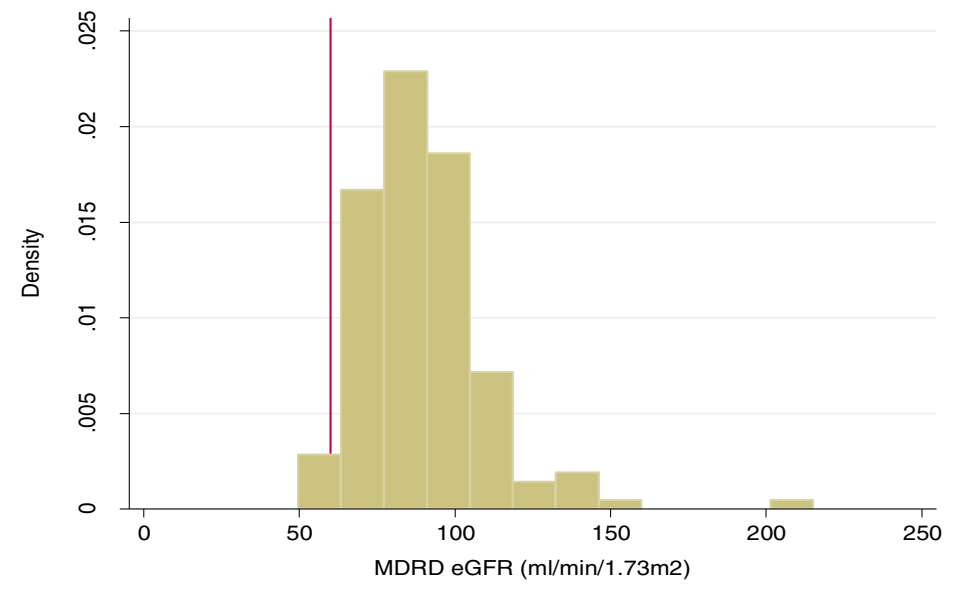

Figure 1 Histograms of MDRD eGFR for rural non-migrants, rural-urban migrants and urban non-migrants. a) Rural non-migrants. b) Rural-urban migrants. c) Urban non-migrants. 
life years with eGFR in migrants. The relationship was examined within tertiles generated from urban life years compared to rural non-migrants as the baseline comparator group, and sequentially adjusted results are shown including adjustments for known vascular disease risk factors and body composition, including measured muscle mass (Table 2). Results were similar for men and women. As the number of urban life years increased, eGFR declined though there was no obvious dose response effect (eGFR for tertiles 2 and 3 compared to baseline;-4.72,-4.67 ml/ $\mathrm{min} / 1.73 \mathrm{~m}^{2}$; $\mathrm{p}$ value for trend $=0.008$ ) suggesting that the relationship may plateau rather than show a linear doseresponse pattern. After adjustment for muscle mass, the associations were attenuated, suggesting limited power ( $\mathrm{p}$ value for trend $=0.08$ ). Further adjustment for HOMAIR, diabetes, smoking, cholesterol, hypertension and BMI weakened the association further to a small degree, although the estimates remained stable in size, the confidence intervals were wide ( $\mathrm{p}$ value for trend $=0.11$ ).

The analysis was repeated with 'proportion of life spent resident in an urban area', and the same pattern found (data not shown).

\section{Discussion}

This study examines the effect of urban migration on renal function in an Indian population. Urbanization appears to be associated with reduced MDRD-derived eGFR. This association appears in part explained by a higher muscle mass with a small contribution from adverse vascular risk factors. These findings suggest that any eGFR comparisons between rural areas and urban areas in India should adjust for muscle mass. The finding of higher muscle mass in urban residents may not have been expected. The physical activity of the rural non-migrants is likely to be greater than that of urban residents but this may be mitigated by nutritional factors such as dietary protein. It is possible that because our sample is relatively young and fit, physical activity levels may be similar at these ages.

In addition, there was a suggestion in this study that poor renal function may be more prevalent in rural areas than previously thought as evidenced by the surprisingly high prevalence of low eGFR.

\section{Rural risk factors for CKD}

The prevalence of CKD stages 3-5 was actually higher in rural non-migrants than both urban migrants and urban non-migrants, although in all groups the number of individuals with CKD was very small. In our study group, smoking prevalence was higher in the rural than the urban population, but this alone is unlikely to fully explain the observed differences. Other factors may be contributing to an increased risk of CKD in rural areas in India. We are not the first to observe such a phenomenon; a similar study examining the prevalence of CKD in Thailand found that developed urban areas had lower prevalence of CKD compared to less-developed rural areas [28]. This was despite the prevalence of diabetes and hypertension being greater in the urban areas, as in our study. The authors speculated that endemic infection, sanitation and access to health care may have influenced this observed difference. Similar reports of high rates of renal disease in rural areas have been made in other South Asian populations. In Sri Lanka clusters of CKD have been reported in male farmers, possibly associated with dietary cadmium $[29,30]$. In India, a number of other factors influencing CKD in rural areas have been postulated, including environmental toxins such as herbal therapies, pesticides and contaminated drinking water, rice and fish [31,32]. In addition, the recently reported 'epidemic' of CKD in agricultural communities in Nicaragua raises a number of other possible infective and nephrotoxic causes, which may be relevant to the Indian setting [33]. Such observations challenge the assumption that CKD in South Asia is primarily because of urbanization and increased diabetes and hypertension.

\section{Urbanization and CKD}

Clear evidence exists of urban life years being associated with a range of vascular risk factors [6,7]. This paper showed that there may also be an association with a decreasing eGFR with years spent in an urban environment, although some of this association may be explained in part by differences in muscle mass. This population is relatively young and fit, and the potential adverse effects of urban living may be more pronounced in a population of people with higher susceptibility to renal damage; those with advanced age and those with a greater number of comorbidities. In addition the early effects of obesity and diabetes mellitus are to cause hyperfiltration [34] and thus an increase' in eGFR if estimated using creatinine based formulae [35]. A study from the 1946 British Birth Cohort suggests that there may be a 20 year lag between the onset of being overweight and the detection of an increased prevalence of CKD [36]. One may therefore expect a substantive lag between first renal insult and actually observing reduced eGFR.

This study has a few limitations: 1) Cross-sectional data As this study is cross-sectional, we can only infer that the observed differences represent declining eGFR with urbanization, and duration of urban life. 2) Creatinine based formulae for estimating renal function In this population renal function was estimated, not measured. The MDRD formula performs less well at the extremes of renal function [27], a significant limitation of estimating rather than measuring renal function. However, a unique strength of this study is the ability of DXA scans to allow adjustment for differences in muscle mass. 3) Lack of chronicity data In clinical practice, the diagnosis of CKD requires evidence 
Table 2 Relationship between urban life years and eGFR $\left(\mathrm{ml} / \mathrm{min} / 1.73 \mathrm{~m}^{2}\right)$

\begin{tabular}{|c|c|c|c|c|c|c|c|c|c|}
\hline \multirow[b]{3}{*}{ Urban life years } & \multirow{2}{*}{\multicolumn{3}{|c|}{ Adjusted for age }} & \multirow{2}{*}{\multicolumn{3}{|c|}{$\begin{array}{l}\text { Adjusted for age and muscle mass } \\
\text { Difference in eGFR between migrants } \\
\text { and non-migrants (reference group } \\
\text { tertile 1) in } \mathrm{ml} / \mathrm{min} / 1.73 \mathrm{~m}^{2}\end{array}$}} & \multirow{2}{*}{\multicolumn{3}{|c|}{$\begin{array}{l}\text { Adjusted for age, muscle mass and } \\
\text { cardiometabolic risk factors* } \\
\text { Difference in eGFR between migrants } \\
\text { and non-migrants (reference group } \\
\text { tertile 1) in } \mathrm{ml} / \mathrm{min} / 1.73 \mathrm{~m}^{2}\end{array}$}} \\
\hline & & & & & & & & & \\
\hline & Men and women & Men & Women & Men and women & Men & Women & Men and women & Men & Women \\
\hline \multirow[t]{3}{*}{ Tertile 2} & -4.72 & -5.67 & -4.65 & -3.90 & -4.02 & -3.91 & -3.35 & -3.32 & -4.11 \\
\hline & $(-8.42,-1.03)$ & $(-10.28,-1.05)$ & $(-10.69,1.39)$ & $(-7.62,-0.18)$ & $(-8.92,0.87)$ & $(-10.08,2.27)$ & $(-7.11,0.41)$ & $(-8.40,1.76)$ & $(-10.14,1.91)$ \\
\hline & $p=0.01$ & $p=0.02$ & $p=0.13$ & $p=0.04$ & $p=0.11$ & $p=0.21$ & $p=0.08$ & $p=0.20$ & $p=0.18$ \\
\hline \multirow[t]{3}{*}{ Tertile 3} & -4.67 & -4.87 & -6.06 & -3.07 & -2.91 & -3.78 & -3.00 & -2.79 & -4.92 \\
\hline & $(-8.42,-1.03)$ & $(-10.28,-1.05)$ & $(-10.69,1.39)$ & $(-7.62,-0.18)$ & $(-8.92,0.87)$ & $(-10.08,2.27)$ & $(-7.11,0.41)$ & $(-8.40,1.76)$ & $(-10.14,1.91)$ \\
\hline & $p=0.01$ & $p=0.05$ & $p=0.03$ & $p=0.10$ & $p=0.25$ & $p=0.20$ & $p=0.12$ & $p=0.28$ & $p=0.10$ \\
\hline$p$ value for trend across tertiles of urban life-years & 0.008 & 0.04 & 0.03 & 0.08 & 0.21 & 0.20 & 0.11 & 0.26 & 0.09 \\
\hline
\end{tabular}


of reduced function for $\geq 3$ months. In this study we have relied on a single eGFR, an approach accepted in epidemiological studies [27], but one that tends to inflate the reported prevalence of CKD by ignoring creatinine fluctuation [37]. In addition, for CVD we have used self-reporting of a diagnosis which we recognise may underestimate the prevalence these conditions. 4) CKD stages 1-2 We do not have information regarding renal tract anatomy or urinalysis, and are therefore unable to make any comment regarding CKD stages 1-2. In order to study the timing of the development and progression of CKD this early stage data is essential. 5) Selection bias Since the study only includes 259 rural non-migrants for 424 urban migrants, the included rural non-migrants, selected by their urban migrant siblings, may well be systematically different from those who didn't participate. 6) Non-generalisability The subjects in this study were sampled by virtue that the index case was a factory worker. Therefore one would need to be very cautious in extrapolating our observational data to the general population. However the purpose of this study was to test a specific hypothesis as regards to the health effects of migration rather than to generalise our observations to the total population (see recent paper on the issue of representativeness) [38].

\section{Conclusions}

As stated, this study is to our knowledge, the first to examine the effect of urbanization on renal function in India. It supports the hypothesis that urbanization has an adverse effect on renal function, and that vascular risk factors such as diabetes and obesity are in part responsible for this difference, but differences in muscle mass also partly account for our observations. Further work is required to confirm this association is seen with measured renal function. Spline regression modelling could be used to try to better characterise at what stage after urban migration there is a slowing in the decline of renal function and how this relates to changes in other risk factors such as blood pressure and obesity. Follow-up data will be of interest. Given the unexpectedly high prevalence of CKD in our rural population, future research should also focus on risk factors for renal disease specific to rural populations.

\section{Additional file}

Additional file 1: Table S1. Correlation and regression estimates between MDRD eGFR and age within different migrant groups, using robust standard errors in the models to allow for any sibling clustering effect. Figure S1. Variation of MDRD eGFR with age within rural non-migrants, rural-urban migrants and urban non-migrants. a) Rural non-migrants. b) Rural-urban migrants. c) Urban non-migrants.

\section{Competing interests}

The authors declare that they have no competing interests.

\section{Authors' contributions}

SK SE YBS KR and HK contributed to study design. HK SK and SE managed the fieldwork, staff training and supervision of the data collection for the study. PB CT and YBS contributed to data analysis. PB CT YBS and DN contributed to data interpretation. $\mathrm{PB}$ wrote the first draft of the paper. $\mathrm{CT}$ YBS and DN contributed to the writing of the paper. All authors provided feedback on the manuscript and approved the submitted version.

\section{Acknowledgements}

The Indian Migration Study was funded by the Wellcome Trust (grant no.WT083707MA)

An abstract of this analysis was presented at the Renal Association conference, UK March 2013

The authors thank the field staff and local investigators who conducted this study. The Indian Migration Study group comprises Prof. K Srinath Reddy, Dr. Dorairaj Prabhakaran, Prof. Tulsi Patel, Dr. Lakshmy Ramakrishnan, Dr. Ruby Gupta, and Dr. Tanica Lyngdoh (New Delhi); Prof. R C Ahuja and Prof. R K Saran (Lucknow); Dr. Prashant Joshi and Dr. N M Thakre (Nagpur); Dr. K V R Sarma, Prof. S Mohan Das, Dr. R K Jain, and Dr. S S Potnis (Hyderabad); Prof. Anura V Kurpad, Dr. Mario Vaz, AV Barathi, and Dr. Murali Mohan (Bangalore); Dr. Chittaranjan Yajnik (Pune); Prof. George Davey Smith and Prof. Yoav Ben Shlomo (Bristol); and Professor Shah Ebrahim and Dr. Sanjay Kinra (London School of Hygiene and Tropical Medicine).

\section{Author details}

${ }^{1}$ The Richard Bright Renal Unit, Southmead Hospital, Bristol BS10 5NB, UK. ${ }^{2}$ London School of Hygiene and Tropical Medicine, London WC1E 7HT, UK. ${ }^{3}$ National Institute of Nutrition, Hyderabad, India. ${ }^{4}$ School of Social and Community Medicine, University of Bristol, Canynge Hall, Bristol BS8 2PS, UK

Received: 9 July 2013 Accepted: 29 October 2013

Published: 31 October 2013

\section{References}

1. McKay L, Macintyre A, Ellaway A: Migration and health: a review of the international literature MRC social and public health sciences unit. In Occasional paper series number 12. Edited by Petticrew M, Hunt K. Glasgow: MRC Social and Public Health Sciences Unit; 2003.

2. Torun B, Stein AD, Schroeder D, Grajeda R, Conlisk A, et al: Rural-to-urban migration and cardiovascular disease risk factors in young Guatemalan adults. Int J Epidemiol 2002, 31(1):218-226.

3. Steffen PR, Smith TB, Larson M, Butler L: Acculturation to Western society as a risk factor for high blood pressure: a meta-analytic review. Psychosom Med 2006, 68(3):386-397.

4. Ramachandran A, Snehalatha C, Latha E, Manoharan M, Vijay V: Impacts of urbanisation on the lifestyle and on the prevalence of diabetes in native Asian Indian population. Diabetes Res Clin Pract 1999, 44(3):207-213.

5. Gupta R, Joshi P, Mohan V, Reddy KS, Yusuf S: Epidemiology and causation of coronary heart disease and stroke in India. Heart 2008, 94(1):16-26.

6. Kinra S, Andersen E, Ben-Shlomo Y, Bowen L, Lyngdoh T, et al: Association between urban life-years and cardiometabolic risk. Am J Epidemiol 2011 174(2):154-164.

7. Ebrahim S, Kinra S, Bowen L, Andersen E, Ben-Shlomo Y, Indian Migration Study group, et al: The effect of rural-to-urban migration on obesity and diabetes in India: a cross-sectional study. PLoS Med 2010, 7(4):e1000268.

8. Barnett AH, Dixon AN, Bellary S, Hanif MW, O'hare JP, et al: Type 2 diabetes and cardiovascular risk in the UK south Asian community. Diabetologia 2006, 49:2234-2246.

9. Landman J, Cruickshank J: A review of ethnicity, health and nutritionrelated diseases in relation to migration in the United Kingdom. Public Health Nutr 2001, 4:647-657.

10. Roderick PJ, Raleigh VS, Hallam L, Mallick NP: The need and demand for renal replacement therapy in ethnic minorities in England. $J$ Epidemiol Community Health 1996, 50(3):334-339.

11. Burden AC, MCNally PG, Feehally J, Walls J: Increased incidence of end-stage renal failure secondary to diabetes mellitus in Asian ethnic groups in the United Kingdom. Diabet Med 1992, 9(7):641-645.

12. Mittal S, Kher V, Gulati S, Agarwal LK, Arora P: Chronic renal failure in India. Ren Fail 1997, 19(6):763-770. 
13. Agarwal S, Dash S: Spectrum of renal diseases in Indian adults. J Assoc Physicians India 2000, 48(6):594-600.

14. Mani MK: Chronic renal failure in India. Nephrol Dial Transplant 1993, 8(8):684-689.

15. Rajapurkar MM, John GT, Kirpalani AL, Abraham G, Agarwal SK, et al: What do we know about chronic kidney disease in India: first report of the Indian CKD registry. BMC Nephrol 2012, 13(1):10.

16. Reddy KS, Prabhakaran D, Chaturvedi V, Jeemon P, Thankappan KR, et al: Methods for establishing a surveillance system for cardiovascular diseases in Indian industrial populations. Bull World Health Organ 2006, 84(6):461-469.

17. Lyngdoh T, Kinra S, Shlomo YB, Reddy S, Prabhakaran D, Indian migration study group, et al: Sib-recruitment for studying migration and its impact on obesity and diabetes. Emerg Themes Epidemiol 2006, 3(1):2.

18. International Institute for Population Sciences (IIPS): National Family Health Survey (NFHS-3); 2007. www.nfhsindia.org/nfhs3.html.

19. National Institute of Clinical Excellence Clinical Guideline 127 (CG127) Hypertension: Management of hypertension in adults in primary care. London (UK): National Institute for Health and Clinical Excellence (NICE); 2011. August.

20. Alberti K, Zimmet P: Definition, diagnosis and classification of diabetes mellitus and its complications: report of a WHO consultation Part 1: diagnosis and classification of diabetes mellitus. Geneva: WHO; 2002.

21. Levy J, Matthews D, Hermans M: Correct homeostasis model assessment (HOMA) evaluation uses the computer program. Diabetes Care 1998, 21(12):2191-2192

22. Duseja A, Thumburu KK, Das A, Dhiman RK, Chawla YK, et al: Insulin tolerance test is comparable to homeostasis model assessment for insulin resistance in patients with nonalcoholic fatty liver disease. Indian J Gastroenterol 2007, 26(4):170-173.

23. Wang ZM, Visser M, Ma R, Baumgartner RN, Kotler D, et al: Skeletal muscle mass: evaluation of neutron activation and dual-energy X-ray absorptiometry methods. J Appl Physiol 1996, 80(3):824-831.

24. Mosteller R: Simplified calculation of body-surface area. N Engl J Med 1987, 317(17):1098

25. Bailey PK, Tomson CR, Kinra S, Ebrahim S, Radhakrishna KV, et al: Differences in estimation of creatinine generation between renal function estimating equations in an Indian population: cross-sectional data from the Hyderabad arm of the Indian migration study. BMC Nephrol 2013, 14:30.

26. National Kidney Foundation: KDOQI clinical practice guidelines for chronic kidney disease: evaluation, classification, and stratification. Am J Kidney Dis 2002, 39:S1-S266.

27. Levey AS, de Jong PE, Coresh J, El Nahas M, Astor BC, et al: The definition, classification, and prognosis of chronic kidney disease: a KDIGO controversies conference report. Kidney Int 2011, 80(1):17-28.

28. Perkovic V, Cass A, Patel AA, Suriyawongpaisal P, Barzi F, InterASIA Collaborative Group, et al: High prevalence of chronic kidney disease in Thailand. Kidney Int 2008, 73(4):473-479.

29. Bandara JM, Senevirathna DM, Dasanayake DM, Herath V, Bandara JM, et al Chronic renal failure among farm families in cascade irrigation systems in Sri Lanka associated with elevated dietary cadmium levels in rice and freshwater fish (Tilapia). Environ Geochem Health 2008, 30:465-478.

30. Wanigasuriya KP, Peiris-John RJ, Wickremasinghe R, Hittarage A: Chronic renal failure in North Central Province of Sri Lanka: an environmentally induced disease. Trans R Soc Trop Med Hyg 2007, 101(10):1013-1017.

31. Jha V: Herbal medicines and chronic kidney disease. Nephrology 2010 15(1):10-17

32. Jha V, Chugh K: Nephropathy associated with animal, plant, and chemical toxins in the tropics. Semin Nephrol 2003, 23(1):49-65.

33. Weiner DE, McClean MD, Kaufman JS, Brooks DR: The Central American Epidemic of CKD. Clin J Am Soc Nephrol 2013, 8(3):504-511.

34. Sasson AN, Cherney DZ: Renal hyperfiltration related to diabetes mellitus and obesity in human disease. World J Diabetes 2012, 3(1):1-6.

35. Huang SH, Sharma AP, Yasin A, Lindsay RM, Clark WF, et al: Hyperfiltration affects accuracy of creatinine eGFR measurement. Clin J Am Soc Nephrol 2011, 6(2):274-280

36. Silverwood RJ, Pierce M, Thomas C, Hardy R, Ferro C, on behalf of the National Survey of Health and Development Scientific and Data Collection Teams, et al: Association between younger age when first overweight and increased risk for CKD. J Am Soc Nephrol 2013, 5:813-21.
37. de Lusignan S, Tomson C, Harris K, van Vlymen J, Gallagher H: Creatinine fluctuation has a greater effect than the formula to estimate glomerular filtration rate on the prevalence of chronic kidney disease. Nephron Clin Pract 2011, 117(3):213-224.

38. Rothman KJ, Gallacher JEJ, Hatch EE: Why representativeness should be avoided. Int J Epidemiol 2013, 42:1012-1014.

doi:10.1186/1471-2369-14-240

Cite this article as: Bailey et al:: The effect of rural-to-urban migration on renal function in an Indian population: cross-sectional data from the Hyderabad arm of the Indian Migration Study. BMC Nephrology 2013 14:240.

\section{Submit your next manuscript to BioMed Central and take full advantage of:}

- Convenient online submission

- Thorough peer review

- No space constraints or color figure charges

- Immediate publication on acceptance

- Inclusion in PubMed, CAS, Scopus and Google Scholar

- Research which is freely available for redistribution

Submit your manuscript at www.biomedcentral.com/submit
C Biomed Central 